\title{
Resource and niche differentiation mechanisms by sympatric Early Pleistocene ungulates: the case study of Coste San Giacomo
}

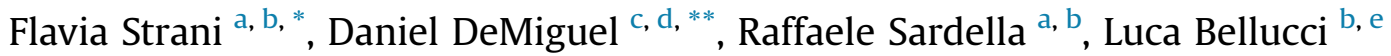 \\ a Dipartimento di Scienze della Terra, Sapienza - Università di Roma, P.le Aldo Moro 5, 00185, Roma, Italy \\ ${ }^{\mathrm{b}}$ Istituto Italiano di Paleontologia Umana, Piazza R. Bonghi 2, 03012, Anagni, Frosinone, Italy \\ c Institut Català de Paleontologia Miquel Crusafont, Edifici Z, C/ de les Columnes s/n, Universitat Autònoma de Barcelona, 08193, Cerdanyola del Vallès, \\ Barcelona, Spain \\ d Departamento de Ciencias de la Tierra, Área de Paleontología, Universidad de Zaragoza, Zaragoza, Spain \\ e Polo museale Sapienza, Sapienza - Università di Roma, P.le Aldo Moro 5, 00185, Roma, Italy
}

\section{A R T I C L E I N F O}

\section{Article history:}

Received 21 December 2016

Received in revised form

15 July 2017

Accepted 29 August 2017

Available online $\mathrm{xxx}$

\section{Keywords:}

Palaeoecology

Dietary partitioning

Body mass

Mesowear

Artiodactyls

Perissodactyls

\begin{abstract}
A B S T R A C T
Resource competition and niche partitioning among the exceptionally high number of sympatric ungulates of the Early Pleistocene site of Coste San Giacomo (Central Italy) is here examined through the study of their dietary proclivities and body size. The main aim of this study is to investigate the niche differentiation mechanisms that let the fossil ungulates coexist in the same region. We also provide information about the complementarity of two different methodologies that observe diet variation at a different time scales (inner and outer mesowear) in the study of dental wear patterns of fossil ungulates. Results from analyses of dental wear degree and body masses predictions show that a wide range of feeding behaviours were adopted by the taxonomical groups (i.e., cervids, bovids and equids) in order to avoid competition. Among larger ungulates diet ranges from strict browsing (Eucladoceros sp., Gazellospira torticornis), to mixed feeding (Gallogoral meneghinii, Leptobos sp.) to pure grazing (Equus stenonis), whereas smaller taxa are more selective feeders (Axis cf. lyra, Croizetoceros cf. ramosus) with only one exception (Gazella borbonica). When taxa with the same feeding behaviour occurred in the same habitat, competition was minimised by differences in body size.
\end{abstract}

() 2017 Elsevier Ltd and INQUA. All rights reserved.

\section{Introduction}

Competition between species occurs when species occupy the same habitat, use the same resources and when said resources are limiting. Ungulates can directly compete for shared resources of food or space, or can interfere against resources used by another species (interference competition) (Latham, 1999). Niche differentiation mechanisms, such as habitat segregation, differences in body weights and specialized dietary adaptations as well as beneficial interactions (facilitation), can however minimize competition allowing the co-existence of different sympatric ungulate in a

\footnotetext{
* Corresponding author. Dipartimento di Scienze della Terra, Sapienza - Università di Roma, P.le Aldo Moro 5, 00185, Roma, Italy.

** Corresponding author. Institut Català de Paleontologia Miquel Crusafont, Edifici Z, C/ de les Columnes s/n, Universitat Autònoma de Barcelona, 08193, Cerdanyola del Vallès, Barcelona, Spain.

E-mail addresses: flavia.strani@uniroma1.it (F. Strani), daniel.demiguel@icp.cat (D. DeMiguel).
}

region, (De Boer and Prins, 1990; Klein and Bay, 1994; Latham, 1999; Prins et al., 2006; Sietses et al., 2009). Such ecological mechanisms in fossil assemblages are often difficult to investigate, but they are indeed important to understand interspecific relationship among taxa, especially in those localities where multiple fossil ungulates occurred and overlapped. In extant herbivore ungulates, diet quality and body size are strongly related (Henley and Ward, 2006; Codron et al., 2007), with the former decreasing when body size increases (Mysterud, 1998; references within; Codron et al., 2007) and with animals of similar body mass and digestive system foraging on similar foods (Henley and Ward, 2006). This is because larger herbivores require larger quantities of food, and the more abundant plants parts (e.g. stems or twigs) are generally of lower nutritional quality than less abundant, higher-quality parts (e.g. leaves, fruits or forbs). Contrarily, smaller herbivores require smaller quantities of food, and they are generally selective feeders adapting to use mostly high quality forage (Clauss et al., 2013). As a result, herbivores exhibiting different body size and different dietary preferences can coexist in the same ecosystem (Prins and Olff, 
1998).

The Early Pleistocene large mammal assemblage of Coste San Giacomo (herein referred as CSG) in Anagni (Central Italy), recently dated around 2.1 Ma (Bellucci et al., 2014), is characterized by an unusual abundance of herbivore taxa, mostly represented by artiodactyls and perissodactyls (Bellucci et al., 2012; Strani et al., 2015). Among these, three fossil cervids (Axis cf. lyra, Croizetoceros cf. ramosus and Eucladoceros sp.), four bovids (Gallogoral meneghinii, Gazella borbonica, Gazellospira torticornis and Leptobos sp.), and one equid (Equus stenonis) have been identified (Bellucci et al., 2012; Bellucci and Sardella, 2015). These taxa have been recently studied from a paleodietary point of view in order to gain new information about the palaeoclimate and palaeoenvironmental conditions that prevailed in Central Italy during the Gelasian (Early Pleistocene) through the analysis of their dental wear degree (mesowear) and molar crown height (hypsodonty) (Strani et al., 2015).

With this new updated information of their dietary preferences, this research relies on the working hypothesis that the extraordinary number of herbivore ungulates werw forced to exhibit different mechanisms in CSG in order to avoid strong direct competition, partition the niche space and optimize exploitation of the available vegetation. We consider indeed CSG as an exceptional case study to do this because of the wide spectrum of diets and body sizes exhibited, and the occurrence of different taxonomic groups in the same assemblage. To do so, we focus on new traits of ecological relevance (e.g., body size) and more precise dietary inferences also adopting the new inner mesowear approach (Solounias et al., 2014) to better understand how niche and resource partitioning work in fossil communities. Importantly, and given the abundant dietary data provided by the CSG mammal community, here we also aim to examine the complementary nature of two proxy methods based on the dental wear degree (inner and outer mesowear) comparing the obtained results and test their combined use in paleoecological studies.

\section{Material and methods}

The studied fossil material belongs to the Early Pleistocene (Gelasian) locality of Coste San Giacomo (CSG) near the town of Anagni (Frosinone, Central Italy). Extensive fieldwork has been carried out since 1978 by researchers of the Italian Institute of Human Palaeontology (IsIPU) (Segre Naldini et al., 2009; Bellucci et al., 2014 and references therein). The material is currently housed at the IsIPU laboratory in Anagni (Frosinone, Central Italy). The updated faunal list of CSG (Bellucci et al., 2014) comprises 19 large and 7 micromammal taxa. Among them, the fossil material here studied consists of 102 dental (molar) specimens of the following ungulate taxa: Axis cf. lyra, Croizetoceros cf. ramosus, Eucladoceros sp., Gazella borbonica, Gazellospira torticornis, Gallogoral meneghinii, Leptobos sp. and Equus stenonis.

\subsection{Body mass estimation}

Herbivore body mass is an important ecological trait in niche repartitioning as it influences diet choices (Henley and Ward, 2006). Mammalian body size is usually predicted by proximal limb bones (Scott, 1983, 1990), cranial (MacFadden and Hulbert, 1990) or dental (Janis, 1990) measurements. Due to the lack of well represented post-cranial and cranial remains for most of the CSG ungulates, only dental measurements were taken. The occlusal lengths of upper second (M2) or lower first (m1) molars were used to estimate body size following the procedure described by Janis (1990). The intercepts and slopes of prediction equations for the different cranio-dental measurements for 1) perissodactyls, 2) cervids only and 3) bovids only were taken from Janis (1990). That is, in order to predict the weight of the CSG taxa, we used the provided slopes and intercepts of the linear regressions based on $\log \mathrm{M} 2$ and $\log \mathrm{m} 1$ occlusal length, form the "Perissodactyls and hyracoids only" group (for E. stenonis), from the "Cervids only group" (for Axis cf. lyra, Croizetoceros cf. ramosus, Eucladoceros sp.), and from the "Bovids only group" (for Gazella borbonica, Gazellospira torticornis and Gallogoral meneghinii). The inverse logarithm was calculated to obtain the body mass for each animal.

The results were compared with modern taxa listed in Janis (1990). Note that body size estimation for Leptobos sp. was not performed due to the lack of both $\mathrm{M} 2$ and $\mathrm{m} 1$ specimens for this taxon.

\subsection{Dental mesowear}

Mesowear is considered a good dietary indicator in herbivore species, as it represents the cumulative effects of the items ingested (both foods and exogenous particles such as dust and grit) on the dental morphology that are produced in a long period of time compared to the lifespan of the animal (Fortelius and Solounias, 2000).

Traditional mesowear (Fortelius and Solounias, 2000), referred as “outer mesowear" (Solounias et al., 2014; Danowitz et al., 2016), analyses the sharpness (i.e., morphology) of the cusps and the height of the occlusal relief of the most labial enamel bands of upper molars and the most lingual of the lower ones (Kaiser and Solounias, 2003; DeMiguel et al., 2012). In Strani et al. (2015), occlusal relief (high or low) and cusp shape (sharp, rounded or blunt) of the apex of the paracone and metacone of the M1-M3 and the metaconid and entoconid of the $\mathrm{m} 1-\mathrm{m} 3$ were examined and scored, and data compared with those of a database of extant ungulates with known diets (Fortelius and Solounias, 2000). The variables were also converted to a score following Rivals et al. (2009) as follows: (0) teeth showing a combination of high relief and sharp cusps; (1) teeth with high relief and rounded cusps; (2) teeth with low relief and rounded cusps; (2.5) teeth with low relief and sharp cusps; and (3) teeth with low relief and blunt cusps.

The inner mesowear method, recently developed by Solounias et al. (2014), analyses instead the second enamel band that forms the lingual margin of the metacone or paracone from an occlusal view, which is generally more frequently preserved in fossil specimens. Inner mesowear reflects dietary preferences that are intermediate in time (days-weeks; Danowitz et al., 2016) between outer mesowear (months-years; Fortelius and Solounias, 2000; Mihlbachler et al., 2011; Sánchez-Hernández et al., 2016) and dental microwear (days-hours; Solounias and Semprebon, 2002). For inner mesowear, the enamel band is scored on the mesial and distal sides of the metacone using a 4 point scaling system described by Solounias et al. (2014) and Danowitz et al. (2016): (1) flat and planar with no gouges or indentations on the surface of the enamel; (2) nearly flat with several gouges that traverse the surface from either edge - the labial and lingual edges of the enamel band are somewhat rounded; (3) similar to score 2, but more rounded with less defined edges and more gouges; and (4) rounded-the surface is smooth without gouges, and there are no well-defined edges. The junction of the mesial and distal sides termed $\mathrm{J}$ is similarly scored: (1) it joins at a sharp, well-defined junction; (2) it is somewhat sharp, and often contains a gouge; (3) it is rounded, but the mesial and distal sides appear as distinct, separate surfaces; and (4) the J point lacks a discrete apex, and the mesial and distal sides of the enamel band form one continuous surface. The method was originally applied by Solounias et al. (2014) only on upper second molars (M2), and here it has been extended to M1 and M3 molars of different individuals in order to widen the sample and 
allow for more complete comparisons among mesowear databases (Table 1). Whenever possible, we used the enamel band of the metacone of the upper molars. If this region was taphonomically damaged, the band of the paracone was examined. We compared our results of the average inner mesowear scores of the mesial, J point and distal surfaces with those of a comprehensive database (Danowitz et al., 2016) of 8 extant ungulates with well-studied diets (browsing, mixed feeding and grazing).

\subsection{Statistical methods}

Discriminant analyses were performed to analyse the resolution of both outer and inner mesowear variables applied to the fossil taxa. For the outer mesowear, the percentage of high relief, rounded and blunt cusps were used as independent variables and two dietary (conservative and radical; Fortelius and Solounias, 2000) classifications were used alternately as a grouping variable in order to recognize those taxa that although showing mixed-feeders adaptations had diets engaged in either browse or grass consumption. For the inner mesowear, we used the diet of extant species (Danowitz et al., 2016) as a grouping variable, and the mesial, distal and $\mathrm{J}$ point scores as variables to infer the dietary preferences of species. All analyses were performed using SPSS Statistics 23.

\section{Results}

\subsection{Body mass estimation}

For the cervids, the body mass has been estimated around $84 \mathrm{~kg}$ for Axis cf. lyra (comparable to the extant mule deer Odocoileus hemionus; 91/57 kg; Janis, 1990), $63 \mathrm{~kg}$ for Croizetoceros cf. ramosus (similar to that of the modern sika deer Cervus nippon [64/41 kg; (Janis, 1990)] and the fallow deer Dama dama [67/44 kg; (Janis, 1990)], and around $239 \mathrm{~kg}$ for Eucladoceros sp. (comparable to the wapiti Cervus canadensis; 400/250 kg; Janis, 1990). With regard to the bovids, the body mass of Gallogoral meneghinii is around $217 \mathrm{~kg}$ (comparable to the extant takin Budorcas taxicolor; $250 \mathrm{~kg}$; Janis, 1990), $30 \mathrm{~kg}$ for Gazella borbonica (similar to the dibatag Ammodorcas clarkei) and $214 \mathrm{~kg}$ for Gazellospira torticornis (comparable to the mountain nyala Tragelaphus buxtoni; 216/150 kg; Janis, 1990). Finally, the body mass of the equid Equus stenonis is around $386 \mathrm{~kg}$ (thus being similar to that of the Grévy's zebra Equus grevyi; $400 \mathrm{~kg}$; Janis, 1990).

\subsection{Outer (traditional) mesowear}

Analyses of outer mesowear of ungulates from CSG (Strani et al., 2015) show different patterns of wear and a wide spectrum of feeding behaviours, with cervids (Axis cf. lyra, Croizetoceros cf. ramosus and Eucladoceros sp.) and the bovid G. torticornis having a predominance of sharp cusps and high occlusal relief and browser diets; the bovids G. borbonica, G. meneghinii and Leptobos sp. showing sharp and rounded cusps and high relief and intermediate diets; and the equid E. stenonis showing blunt and rounded cusps and low relief and a strict grazer behaviour (Table 1 ).

\subsection{Inner mesowear}

The distribution of the inner mesowear scores (mesial, J point and distal) of the ungulate community of CSG includes mostly intermediate values (from 1 to 3 ) (Table 2). The highest ones ( $>3$ ) are observed in E. stenonis. When plotting data from CSG with those of modern ungulates grouped into browsers, mixed feeders and grazers (Fig. 1), the scores distribution suggests a spectrum of dietary preferences that extend from browsing to mixed feeding, with the exception of $E$. stenonis. The scores of $A$. cf. lyra, $C$. cf. ramosus, Eucladoceros sp., and G. torticornis are comparable to those of modern browsers and a high variability of the mesial and distal scores are observed (though the J point score tends to have similar values). G. meneghinii scores are similar to those of a browser as well, while higher scores are observed in Leptobos sp. and $G$. borbonica which are placed close to mixed feeders. These results should however be taken as tentative due to the small sample available for these taxa $(\mathrm{N}=2)$. E. stenonis differs by being the only species whose average inner mesowear scores are comparable to those of modern grazers.

\subsection{Discriminant analyses}

Discriminant analysis performed with the outer mesowear variables provides a satisfactory dietary discrimination with $74.1 \%$ of extant taxa (68.5\% in cross-validation, $\mathrm{p}<0.001$ for Function 1 , and $\mathrm{p}=0.38$ for Function 2 with canonical correlation of 0.80 and 0.35 ) correctly classified according to a conservative classification and $74.1 \%$ ( $74.1 \%$ in cross-validation, $\mathrm{p}<0.001$ for Function 1, and $\mathrm{p}=0.50$ for Function 2 with canonical correlation of 0.80 and 0.16 ) according to the radical one. Bivariate diagrams based on the discriminant analysis (Fig. 2A-B) show that all the fossil deer and the antelope G. torticornis are classified as browser, G. meneghinii, $G$. borbonica as mixed feeders, and E. stenonis as a grazer in both the conservative (Fig. 2A) and radical (Fig. 2B) classifications. Leptobos sp. is classified as a mixed feeder in the conservative classification (Fig. 2A), and considered as a grazer in the radical (Fig. 2B).

Discriminant analyses for the inner mesowear predicted the diet of the individuals with a high accuracy rate (73,6\% of cases correctly classified; $71,3 \%$ in cross-validation) resulted in two significant discriminant functions ( $\mathrm{p}<0.001$ for Function 1 , and $\mathrm{p}=0.74$ for Function 2) with canonical correlation of 0.80 and 0.08 . Note that

Table 1



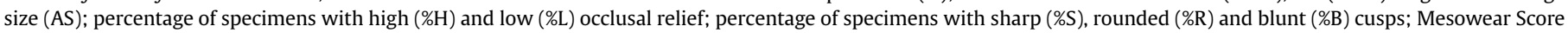
(MS); mesial (Mesial), distal (Distal) and J point (J) scores; and diet classification (Diet). Outer mesowear data from Strani et al. (2015).

\begin{tabular}{|c|c|c|c|c|c|c|c|c|c|c|c|c|c|c|}
\hline \multirow[t]{2}{*}{ Species } & \multicolumn{3}{|c|}{ Body Mass (kg) } & \multicolumn{7}{|c|}{ Outer Mesowear } & \multicolumn{4}{|c|}{ Inner Mesowear } \\
\hline & M2 L (N) & M1 L (N) & AS & $\mathrm{N}$ & $\% \mathrm{H}$ & $\% \mathrm{~L}$ & $\% \mathrm{~S}$ & $\% \mathrm{R}$ & $\% \mathrm{~B}$ & MS & $\mathrm{N}$ & Mesial & Distal & $\mathrm{J}$ \\
\hline Axis cf. lyra & $75.87(2)$ & $92.89(5)$ & 84.38 & 26 & 100 & 0 & 76.9 & 23.1 & 0 & 0.19 & 7 & 1.5 & 1.8 & 1.43 \\
\hline Croizetoceros cf. ramosus & 1 & $63.39(1)$ & 63.39 & 5 & 100 & 0 & 80 & 20 & 0 & 0.2 & 3 & 1 & 1.5 & 1.67 \\
\hline Eucladoceros sp. & $214.70(3)$ & $263.13(1)$ & 239.9 & 26 & 100 & 0 & 88.5 & 11.5 & 0 & 0.12 & 12 & 1.3 & 1.5 & 1.83 \\
\hline Gazella borbonica & $31.08(1)$ & $28.74(3)$ & 29.91 & 8 & 87.5 & 12.5 & 50 & 50 & 0 & 0.63 & 2 & 2.5 & 2.5 & 3 \\
\hline Gazellospira torticornis & $214.44(4)$ & 1 & 214.4 & 8 & 100 & 0 & 87.5 & 12.5 & 0 & 0.13 & 4 & 1.5 & 1 & 1.75 \\
\hline Gallogoral meneghini & $217.27(1)$ & i & 217.3 & 2 & 100 & 0 & 50 & 50 & 0 & 0.5 & 2 & 1.5 & 1 & 2 \\
\hline Leptobos sp. & 1 & i & I & 2 & 100 & 0 & 0 & 100 & 0 & 1 & 2 & 2.5 & 2.5 & 2.5 \\
\hline Equus stenoni & $303.17(5)$ & $468.77(4)$ & 387 & 21 & 4.8 & 95.2 & 28.6 & 38.1 & 28.6 & 2.33 & 11 & 3.33 & 3.29 & 3.63 \\
\hline
\end{tabular}


Table 2

Dietary predictions from discriminant analysis using inner mesowear variables.

\begin{tabular}{|c|c|c|c|c|}
\hline Species & Frequency Browser & Frequency Mixed Feeder & Frequency Grazer & Undetermined \\
\hline Axis cf. lyra & 4 & & & 3 \\
\hline Croizetoceros cf. ramosu & 2 & & & 1 \\
\hline Eucladoceros sp. & 8 & & & 4 \\
\hline Gazella borbonica & & 2 & & \\
\hline Gazellospira torticornis & 2 & & & \\
\hline Gallogoral meneghinii & 1 & & & 1 \\
\hline Leptobos sp. & 1 & 1 & & \\
\hline Equus stenonis & & 1 & 5 & 5 \\
\hline
\end{tabular}

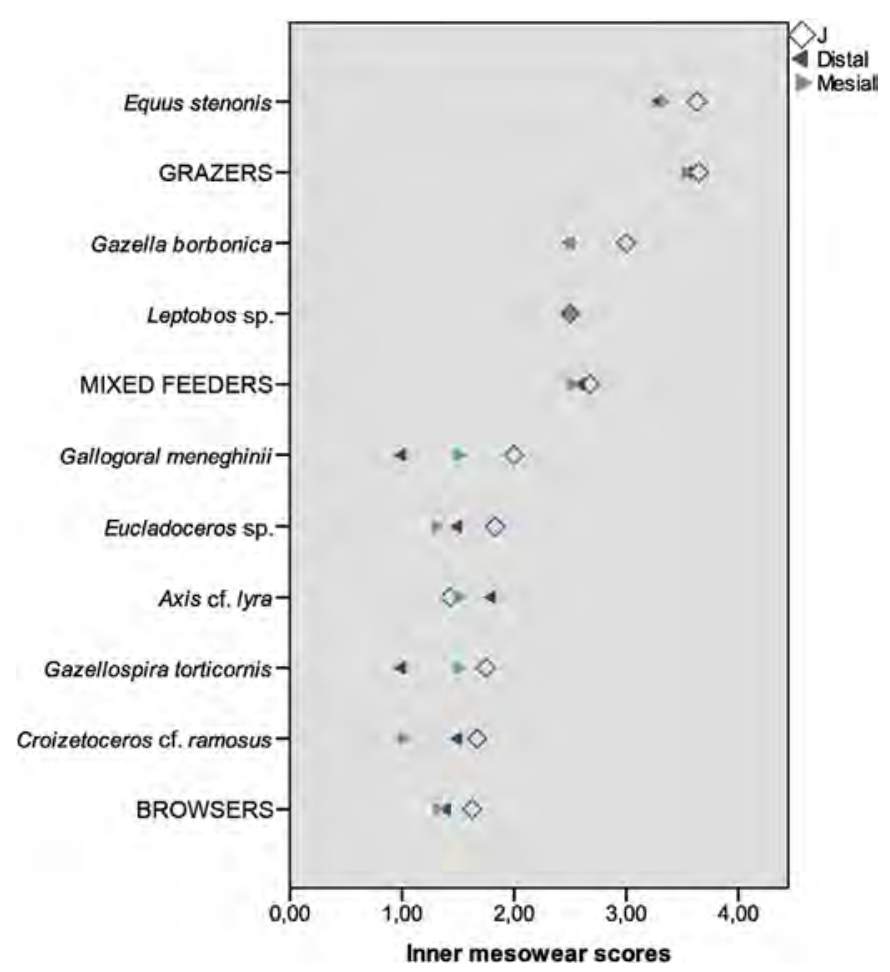

Fig. 1. Mean inner mesowear scores for fossil taxa and modern browsers, mixed feeders and grazers (data for extant species from Danowitz et al., 2016). individuals lacking mesial/distal bands or J scores were not classified (Undetermined). Table 2 depicts individual results of the dental specimens and their variability thus showing that all the suitable individuals of Axis cf. lyra, Croizetoceros cf. ramosus, Eucladoceros sp., Gazellospira torticornis and Gallogoral meneghinii are browsers, Gazella borbonica individuals are mixed feeders, one specimen of Leptobos sp. is considered to be a browser and other a mixed feeder, and most of the individuals of $E$. stenonis are grazers (with only one classified as a mixed feeder).

Globally, inner mesowear results (Table 3) considering both the individual results (Table 2) and the mean distribution of the inner mesowear scores (Fig. 1) show a diversity of dietary preferences. A browsing feeding behaviour can be observed for the cervids as well as for the bovids G. torticornis and G. meneghinii. Results also indicate a mixed feeding behaviour for $G$. borbonica and Leptobos sp., whereas E. stenonis appears to be a grazer.

\section{Discussion}

\subsection{Comparison between outer and inner mesowear}

Both outer and inner mesowear methods show similar dietary predictions for most of the cases (Table 3), and only one discrepancy can be observed according to the primary (conservative classification) diet of the species. Thus, G. meneghinii is classified as a mixed feeder and a browser according to the outer and inner mesowear, respectively. Given that the inner mesowear occurs at a smaller time scale than the outer, this can indicate a mixed feedingtowards-browsing diet type or a temporary shift towards a more browsing feeding behaviour. When the secondary (or more radical)


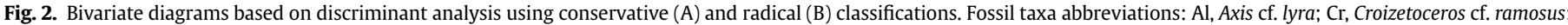
Eu, Eucladoceros sp.; Gb, Gazella borbonica; Gt, Gazellospira torticornis; Gm, Gallogoral meneghinii; Lp, Leptobos sp.; Es, Equus stenonis (data from Strani et al., 2015). 
Table 3

Dietary inference from outer and inner mesowear analyses.

\begin{tabular}{|c|c|c|c|}
\hline \multirow[t]{2}{*}{ Species } & \multicolumn{2}{|l|}{ Outer mesowear } & \multirow{2}{*}{$\begin{array}{l}\text { Inner mesowear } \\
\text { Diet prediction }\end{array}$} \\
\hline & Diet prediction (conservative classification) & Diet prediction (radical classification) & \\
\hline Axis cf. lyra & Browser & Browser & Browser \\
\hline Croizetoceros cf. ramosus & Browser & Browser & Browser \\
\hline Eucladoceros sp. & Browser & Browser & Browser \\
\hline Gazella borbonica & Mixed Feeder & Mixed Feeder & Mixed Feeder \\
\hline Gazellospira torticornis & Browser & Browser & Browser \\
\hline Gallogoral meneghinii & Mixed Feeder & Mixed Feeder & Browser \\
\hline Leptobos sp. & Mixed Feeder & Grazer & Mixed Feeder \\
\hline Equus stenonis & Grazer & Grazer & Grazer \\
\hline
\end{tabular}

diet obtained from the outer mesowear is compared with results from the inner mesowear, there is a discrepancy for Leptobos sp. Inner mesowear scores indicate a mixed feeding behaviour (Table 3 , Fig. 1) thus differing from the grazing diet inferred from the radical classification (Table 3, Fig. 2A-B). This discrepancy may suggest that this taxon leaned generally towards a diet richer in abrasive foods (months-to-years according to the outer mesowear time scale), and that it assumed a more mixed feeding behaviour during short periods of time (days-to-weeks inner mesowear time scale). The small available samples for both these taxa may impact the robusticity of these interpretations, but it must be noted that the discrepancies were obtained between the mixed feeder and the browser/grazer style and, importantly, no species were classified as a grazer while being a browser, and vice versa.

Overall, both methods are here shown to provide very similar (almost identical) results, and it should be noted that the inner mesowear is most effective with specimens where all the three variables can be scored (when all the three parts of the inner second enamel band are not damaged or ruined), as highlighted by the number of undetermined individuals (Table 2). Nevertheless using both methods is highly advantageous and recommendable to obtain information about diet variation at different time scales.

\subsection{Niche and resource partitioning}

All the cervids (Axis cf. lyra, Croizetoceros cf. ramosus and Eucladoceros sp.) share similar dental wear pattern to those of extant browsers. However, the size of the two former differs greatly from that of Eucladoceros sp. by being significantly smaller ( 84 and $63 \mathrm{~kg}$ vs. $239 \mathrm{~kg}$, respectively). It is therefore possible that, despite exhibiting the same type of diet, differences in foraging in terms of height (vertical stratification) and the incorporation of different browse and ligneous foods, may explain the coexistence of the two small deer with Eucladoceros sp. Thus, Eucladoceros due to its larger body size may have exhibited a generally poorer quality diet (such as twigs of ligneous plants) if compared to that of the other cervids, and this could have been more evident during (short) periods of drier conditions and resource limitation. In this adverse periods small browsers would have foraged on most of the scarce high quality foods (see Prins et al., 2006 for an explanation of modern African species). Alcalde (2013) reports post-cranial adaptations for Axis lyra (=Metacervoceros rhenanus) similar to those of some modern browser species (such as the Eurasian elk Alces alces) that dwell and feed on humid areas. Although $A$. alces is significantly larger than all the CSG deer (450/318 kg; Janis, 1990), it has outer and inner mesowear comparable to those of Axis cf. lyra. Both species display high percentage of sharp cusps coupled with mesial, distal and J scores close to 1.5 (Table 2) (Fortelius and Solounias, 2000; Solounias et al., 2014; Danowitz et al., 2016). This suggests that CSG Axis cf. lyra may had preferably browsed in wetlands areas. G. torticornis is the other taxon whose wear patterns reflect a selective (browsing) feeding behaviour and is comparable in size to Eucladoceros sp. (Fig. 3). Because post-cranial morphologies similar to those of modern gazelles have been reported for this fossil antelope (Alcalde, 2013), an adaptation to arid habitats as well as some features typical of woodlands may have been possible. Thus, G. torticornis might have avoided competition with both the medium-sized browser deer Eucladoceros sp. and larger open-land taxa such as the mixed feeders Leptobos sp. and G. meneghinii by browsing on brushes of transitional ecotones (e.g., transition zone between closed woodland and open grassland) or by partitioning the available vegetation in terms of height above ground level (Hulbert and Andersen, 2001) foraging on the same plant species but eating different parts as observed in African Wildebeest and Zebra (Owaga, 1975).

Alcalde (2013) also reports post-cranial adaptations for steep terrains and rather open landscapes for G. meneghinii, thus habitat segregation (i.e. a preference for mountainous regions) combined with a more flexible diet may had been key factors for niche partitioning in G. meneghinii populations. Wear patterns for G. borbonica indicate a mixed feeding (with a probably tendency towards grazing) composed by a higher amount of abrasives in diet if compared to all the cervids and the other bovids from CSG. This seems to be related to an occurrence in more open grasslands habitats (Strani et al., 2015). G. borbonica is also the smallest ungulate of the mammal assemblage (Fig. 3 ) and its broader diet fits well with the coexistence with the other larger mixed feeders Leptobos sp. and G. meneghinii and the strict grazer E. stenonis in

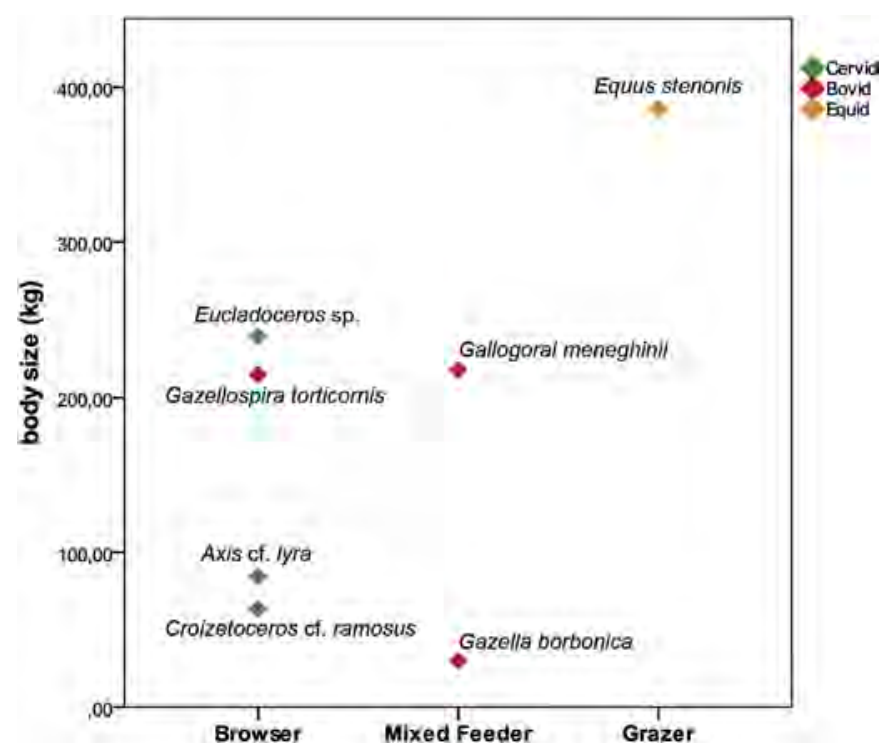

Fig. 3. Average body size ( $\mathrm{kg}$ ) of the CSG ungulates plotted against feeding behaviour. 


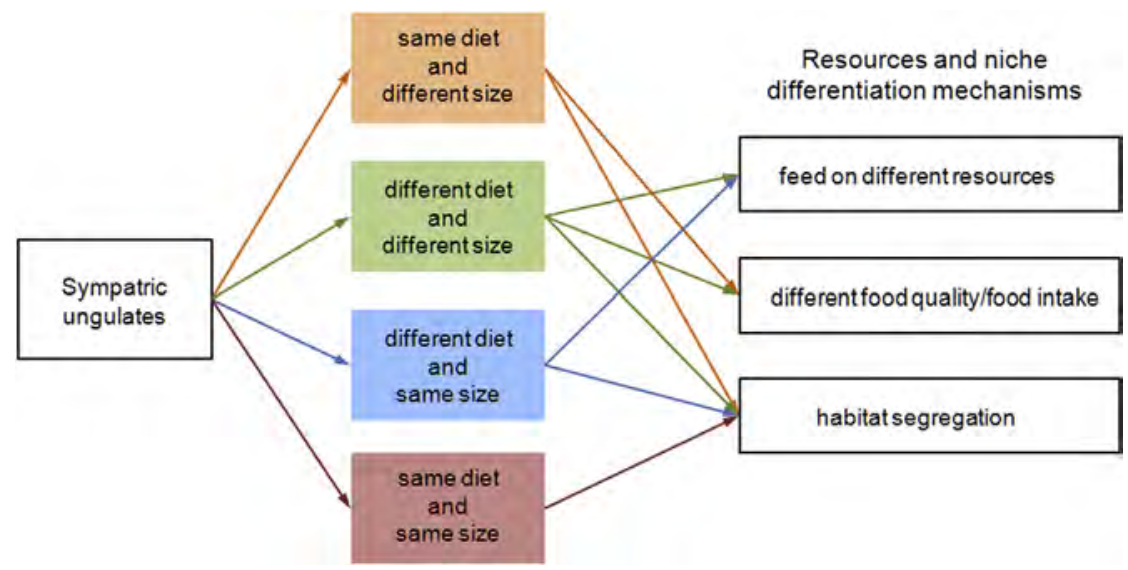

Fig. 4. Flow diagram showing niche partitioning mechanisms in sympatric ungulates based on dietary preferences and body size.

open environments. Overall, larger ungulates tend to display different diet ranging from strict browsing to grazing, whereas small taxa, with the exception of the bovid G. borbonica, appear to be more selective feeders (Fig. 3). It should also be noted that $A$. cf. lyra, Eucladoceros sp. and E. stenonis are the most common and well represented ungulates of the CSG assemblage (Bellucci et al., 2014), and the relative abundance of these species in the fossil deposit most probably influenced niche partitioning among the CSG herbivores as well. According to niche breadth concepts modern assemblage composed of abundant and relatively rare ungulates, uncommon species may persist by either consuming preferably few sparsely but widely available resource types, or by foraging in areas where their favoured resource is concentrated and aren't heavily exploited by the most common species (Brown, 1984; Macandza et al., 2012 and references therein). Following this it can be hypothesize that less common CSG ungulate taxa ( $C$. cf ramosus, G. torticornis, G. borbonica, Leptobos sp., G. meneghinii) had a narrower niche breadth, restricting their diet to selected resources or smaller patches, while the most common species (A. cf. lyra, Eucladoceros sp., E. stenonis) would exploit a broader landscape.

According to all this, we propose a schematic model for explaining the major mechanisms of niche differentiation among sympatric herbivore ungulates based on diet and body masses (Fig. 4).

\section{Conclusions}

Data obtained from this study inform about how niche differentiation occurs in fossil assemblages, which is especially relevant in the study of species coexistence under limiting resources. Using the Early Pleistocene assemblage of Coste San Giacomo as a case study, we see that ungulates sharing the same feeding behaviour (browsing, mixed feeding, grazing) generally have different body size indicating different food intake demands and thus different diet quality. For similar-sized ungulates, a difference in the feeding behaviour is usually observed, and by consuming different type of resources they can share same habitats. For ungulates that share dietary type and body size, differences in habitat preference play a key role in niche partitioning with generalist species feeding in grasslands and woodlands (or in transitional areas), and more specialised taxa foraging mostly in specific environments (e.g., wetlands, rocky regions).

\section{Acknowledgements}

This research was supported by the Sapienza Progetto
Università (projects C26A11SNA3 and C26A12PZA2), the Spanish Ministerio de Economía y Competitividad (project CGL2016-76431P) and CERCA Program (Generalitat de Catalunya). A special thank to 2009 fieldwork co-director Fabio Parenti and to Luciano Bruni, Barthélémy Giannetti, Adelaide De Castro, and Caterina Giovinazzo for their invaluable help, suggestions and assistance. We also thank the 1st IMERP- XIV EJIP committee for organizing the "New insights on Quaternary ecosystems" workshop. Finally we'd like to thank the anonymous reviewers for their comments and suggestions.

\section{References}

Alcalde, G.M., 2013. Caracterización ecomorfológica del esqueleto postcraneal en rumiantes (Artiodactyla, Mammalia): aplicación en la inferencia de las adaptaciones ecológicas de los rumiantes del plio-pleistoceno de España. Ph.D. Thesis. Universidad Complutense de Madrid, Facultad de Ciencias Geológicas, Departamento de Paleontología, Madrid, Spain.

Bellucci, L., Mazzini, I., Scardia, G., Bruni, L., Parenti, F., Segre, A.G., Naldini, E.S. Sardella, R., 2012. The site of Coste San Giacomo (Early Pleistocene, centra Italy): palaeoenvironmental analysis and biochronological overview. Quat. Int 267, 30-39.

Bellucci, L., Bona, F., Corrado, P., Magri, D., Mazzini, I., Parenti, F., Scardia, G., Sardella, R., 2014. Evidence of late gelasian dispersal of African fauna at Coste san Giacomo (Anagni Basin, central Italy): early Pleistocene environments and the background of early human occupation in Europe. Quat. Sci. Rev. 96, 72-85.

Bellucci, L., Sardella, R., 2015. The last antilopini bovids from the early Pleistocene of Italy. Quat. Int. 357, 245-252.

Brown, J.H., 1984. On the relationship between abundance and distribution of species. Am. Nat. 124 (2), 255-279.

Clauss, M., Steuer, P., Müller, D.W.H., Codron, D., Hummel, J., 2013. Herbivory and body size: allometries of diet quality and gastrointestinal physiology, and implications for herbivore ecology and dinosaur gigantism. PLoS One 8 (10), e68714.

Codron, D., Lee-Thorp, J.A., Sponheimer, M., Codron, J., De Ruiter, D., Brink, J.S., 2007 Significance of diet type and diet quality for ecological diversity of African ungulates. J. Anim. Ecol. 76, 526-537.

Danowitz, M., Hou, S., Mihlbachler, M., Hastings, V., Solounias, N., 2016. A combined-mesowear analysis of late Miocene giraffids from North Chinese and Greek localities of the pikermian biome. Palaeogeogr. Palaeoclimatol Palaeoecol. 449, 194-204.

De Boer, W.F., Prins, H.H.T., 1990. Large herbivores that strive mightily but eat and drink as friends. Oecologia 82, 264-274.

DeMiguel, D., Quiralte, V., Azanza, B., Montoya, P., Morales, J., 2012. Dietary behaviour and competition for vegetal resources in two Early Miocene pecoran ruminants from Central Spain. Geodiversitas 34, 425-443.

Fortelius, M., Solounias, N., 2000, Functional characterization of ungulate molars using the abrasioneattrition wear gradient: a new method for reconstructing paleodiets. Am. Mus. Novit. 3301, 1-35.

Henley, S.R., Ward, D., 2006. An evaluation of diet quality in two desert ungulates exposed to hyper-arid conditions. Afr. J. Range Forage Sci. 23 (3), 185-190.

Hulbert, I.A.R., Andersen, R., 2001. Food competition between a large ruminant and a small hindgut fermentor: the case of the roe deer and mountain hare Oecologia 128, 499-508.

Janis, C.M., 1990. Correlation of cranial and dental variables with body size in ungulates and macropoids. In: Damuth, J., MacFadden, B.J. (Eds.), Body Size in Mammalian Paleobiology: Estimation and Biological Implications. Cambridge 
University Press, New York, pp. 255-299.

Kaiser, T.M., Solounias, N., 2003. Extending the tooth mesowear method to extinct and extant equids. Geodiversitas 25 (2), 321-345.

Klein, D.R., Bay, C., 1994. Resource partitioning by mammalian herbivores in the high arctic. Oecologia 97, 439-450.

Latham, J., 1999. Interspecific interactions of ungulates in European forests: an overview. For. Ecol. Manag. 120, 13-21.

Macandza, V.A., Owen-Smith, N., Cain, J.W., 2012. Habitat and resource partitioning between abundant and relatively rare grazing ungulates. J. Zool. 287, 175-185.

MacFadden, B.J., Hulbert, R.C., 1990. Body size estimates and size distribution of ungulate mammals from the late Miocene Love Bone Bed of Florida. In: Damuth, J., MacFadden, B.J. (Eds.), Body Size in Mam- Malian Paleobiology: Estimation and Biological Implications. Cambridge University Press, New York pp. 337-363.

Mihlbachler, M., Rivals, F., Solounias, N., Semprebon, G., 2011. Dietary change and evolution of horses in North America. Science 331, 1178-1181.

Mysterud, A., 1998. The relative roles of body size and feeding type on activity time of temperate ruminants. Oecologia 113, 442-446.

Owaga, M.L., 1975. The feeding ecology of wildebeest and zebra in Athi-Kaputei plains. Afr. J. Ecol. 13, 375-383.

Prins, H.H.T., Olff, H., 1998. Species richness of African Grazer assemblages: towards a functional explanation. In: Newbery, D.M. (Ed.). In: Prins, H.H.T., Brown, N.D (Eds.), Dynamics of Tropical Communities, vol. 37. Blackwell, Oxford, pp. $449-490$

Prins, H.H.T., de Boer, W.F., van Oeveren, H., Correia, A., Mafuca, J., Olff, H., 2006. Coexistence and niche segregation of three small bovid species in southern Mozambique. Afr. J. Ecol. 44, 186-198.

Rivals, F., Schulz, E., Kaiser, T.M., 2009. Late and middle Pleistocene ungulates dietary diversity in Western Europe indicate variations of Neanderthal paleoenvironments through time and space. Quat. Sci. Rev. 28, 3388-3400.

Sánchez-Hernández, C., Rivals, F., Blasco, R., Rosell, J., 2016. Tale of two timescales: combining tooth wear methods with different temporal resolutions to detect seasonality of Palaeolithic hominin occupational patterns. J. Archaeol. Sci. Rep. 6, 790-797.

Scott, K.M., 1983. Body weight prediction in fossil Artiodactyla. Zool. J. Linn. Soc. 77, 199-215.

Scott K.M. 1990. Postcranial dimensions of ungulates as predictors of body mass. In: Damuth, J., Macfadden, B.J. (Eds.), Body Size in Mammalian Paleobiology: Estimation and Biological Implications. Cambridge University Press, New York, pp. 1-335.

Segre Naldini, E., Muttoni, G., Parenti, F., Scardia, G., Segre, A.G., 2009. Nouvelles recherches dans le bassin Plio-Pléistocène d'Anagni (Latium méridional, Italie). L'Anthropologie 113, 66-77.

Sietses, D.J., Faupin, G., de Boer, W.F., de Jong, C.B., Henkens, R.J.H.G., Usukhjargal, D. Batbaatar, T., 2009. Resource partitioning between large herbivores in Hustai National Park, Mongolia. Mamm. Biol. 74, 381-393.

Solounias, N., Semprebon, G., 2002. Advances in the reconstruction of ungulate ecomorphology and application to early fossil equids. Am. Mus. Novit. 3366, $1-49$.

Solounias, N., Tariq, M., Hou, S., Danowitz, M., Harrison, M., 2014. A new method of tooth mesowear and a test of it on domestic goats. Ann. Zool. Fenn. 51, 111-118.

Strani, F., DeMiguel, D., Sardella, R., Bellucci, L., 2015. Paleoenvironments and climatic changes in the Italian Peninsula during the Early Pleistocene: evidence from dental wear patterns of the ungulate community of Coste San Giacomo. Quat. Sci. Rev. 121, 28-35. 